\title{
Alcances sociales y económicos de la implementación de la hipoteca inversa en Chile
}

\author{
José Luis Ruiz, Pablo Tapia y José Donoso
}

\section{Resumen}

Este estudio simula los alcances sociales y económicos de implementar la hipoteca inversa en Chile. Usando la Encuesta de Protección Social (EPS, 2009) y metodologías de simulación recientes se analiza el aporte monetario que lleva aparejado la contratación de este instrumento, que consiste en un sistema de pagos periódicos de manera vitalicia. Los individuos que podrían acceder a la hipoteca inversa serían aquellos pensionados y propietarios de su vivienda, lo que supone el $70 \%$ de la población constituida por personas mayores. El aporte monetario es creciente a tasas que van en aumento en función de la edad en que se contrata la hipoteca inversa. Por último, se señala que el aumento de liquidez tiene un amplio potencial social, pudiendo disminuir un 15\% el índice de pobreza en el grupo objetivo.

\section{Palabras clave}

Vivienda, financiación de la vivienda, hipotecas, pensiones, jubilación, precios, aspectos económicos, modelos matemáticos, aspectos sociales, Chile

\section{Clasificación JEL}

G21, G22, G28

\section{Autores}

José Luis Ruiz Vergara es Profesor Asistente en el Departamento de Administración de la Universidad de Chile. Correo electrónico: jlruiz@fen.uchile.cl.

Pablo Tapia Griñen es Profesor Asistente en el Departamento de Administración de la Universidad de Chile. Correo electrónico: ptapia@fen.uchile.cl.

José Donoso Salas es Magíster en Finanzas de la Universidad de Chile. Correo electrónico: sjdonososa@fen.chile.cl. 


\section{Introducción}

La tendencia demográfica mundial en las últimas décadas es de aumentos en longevidad y en la proporción de personas mayores sobre la población total. Según datos del Instituto Nacional de Estadísticas de Chile (INE), en 1950 la población mayor de 65 años en Chile representaba el 4\% de la población, cifra que ha ido en aumento y que se proyecta alcanzará el 22\% en 2025. Por ende, las personas que forman parte de este grupo etario cobran mayor importancia para el diseño de políticas públicas y representan un desafío para el financiamiento de los sistemas de pensiones. Lo anterior adquiere carácter urgente si consideramos que actualmente las pensiones que reciben los chilenos son bajas en comparación con los países pertenecientes a la Organización para la Cooperación y el Desarrollo Económicos (OCDE) y que el $70 \%$ de la población considera que estas son insuficientes para mantener un nivel de vida adecuado (Comisión Asesora Presidencial sobre el Sistema de Pensiones, 2015).

Una alternativa que puede contribuir a mejorar el nivel de vida de los pensionados es la hipoteca inversa, conocida también como hipoteca revertida o hipoteca reversa. En términos generales, la hipoteca inversa es un producto financiero dirigido a personas jubiladas propietarias de su vivienda, en virtud del cual una institución financiera se compromete a pagar un monto de forma mensual hasta que el contratante fallezca, luego de lo cual la propiedad pasa a posesión del financista, a menos que los herederos devuelvan a la institución financiera el monto total comprometido. El principal objetivo de este instrumento es desbloquear parte de la riqueza ilíquida que representa la propiedad de una vivienda sin que el propietario tenga que dejar de habitarla. Lo anterior conllevaría una serie de beneficios económicos, como son el aumento en la liquidez de los hogares y la obtención de recursos que complementan a la pensión y generan reducción de pobreza entre las personas mayores. Sin embargo, la hipoteca inversa no está presente en Chile, por lo que el objetivo del presente estudio es simular los alcances sociales y económicos que podría generar la implementación de este instrumento financiero.

Para llevar a cabo la investigación se sigue la metodología propuesta por Ma y Deng (2013) y Wang y Kim (2014), a fin de modelar los pagos mensuales de una hipoteca inversa a partir un precio de vivienda ${ }^{1}$. Partiendo de los pagos generados de la hipoteca inversa, se analiza cuál es el aporte de estos al ingreso de la familia y a nivel per cápita, cómo cambian los pagos con respecto a la edad de contratación de la hipoteca inversa una vez pensionado, y en qué medida puede incidir el instrumento en la tasa de pobreza del grupo objetivo.

La hipoteca inversa ha sido analizada en Chile por Muñoz (2011) y por Alonso, Tuesta y Lamuedra (2013). Por su parte, nuestra investigación se enfoca en el potencial social de este instrumento utilizando simulaciones en base a modelamientos actualizados, con variantes como la relación préstamo-valor, el cambio en el precio de los inmuebles y las tasas de mortalidad, entre otras. Estas innovaciones dotan de mayor interés a esta investigación: aunque esté inmersa en un tipo de literatura ampliamente documentada, esto le proporciona una plataforma confiable donde contrastar nuestros hallazgos.

Según nuestro análisis, la contratación de una hipoteca inversa daría lugar a pagos mensuales de 62.508 pesos chilenos en promedio para los contratantes, lo que supone un aumento del 107\% con respecto a la pensión que reciben mensualmente los individuos de la muestra, cuya media es de 58.245 pesos. A su vez, la contribución monetaria del instrumento conlleva un incremento de liquidez correspondiente al $57 \%$ del ingreso per cápita. Además, se presenta evidencia de que a medida que aumenta la edad en que las personas contratan el instrumento se incrementan los pagos que estos

\footnotetext{
1 Estos precios corresponden a la Encuesta de Protección Social 2009 ([véase [en línea]), https://www.previsionsocial.gob.cl/ sps/biblioteca/encuesta-de-proteccion-social/bases-de-datos-eps/.
} 
perciben, ya que aumentan las tasas. Consecuentemente, en el caso de que todas las personas aplicables contraten una hipoteca inversa al momento de jubilarse, el índice de pobreza en este grupo se reduciría aproximadamente en un 15\%. Este resultado puede ser ampliado en caso de aumentar la edad de jubilación de las mujeres a 65 años e igualarla a la de los hombres, llegando a un 19\% de reducción de pobreza.

Luego de la presente introducción el documento prosigue con la sección II, donde se detalla el contexto de las pensiones en Chile. En la sección III se revisa la literatura teórica y empírica de la hipoteca inversa y su potencialidad social. En la sección IV se presentan el marco analítico y los datos de la simulación. En la sección $\vee$ se muestran los resultados de simulaciones. Por último, en la sección VI figuran las conclusiones.

\section{Pensiones en Chile}

Hasta 1980 Chile contaba con un sistema de pensiones basado en el reparto, en virtud del cual las jubilaciones se financiaban en distintas instituciones previsionales llamadas cajas de previsión, con reglas y beneficios diferenciados. Dada la tendencia al envejecimiento de la población y a una menor tasa de trabajadores activos que contribuían a su financiamiento el sistema se volvió insolvente, razón por la cual en 1981 se creó un nuevo sistema de pensiones basado en la capitalización de cuentas individuales para los trabajadores que se incorporan al mercado laboral y en forma voluntaria a quienes venían del sistema antiguo. Quienes se mantuvieron en el sistema antiguo siguieron contribuyendo a este, pero sus jubilaciones se pagan con impuestos generales de la nación. Los afiliados al nuevo sistema de pensiones depositan cotizaciones previsionales en cuentas individuales gestionadas por Administradoras de Fondos de Pensiones (AFP), que a su vez están encargadas de recaudar, registrar e invertir los recursos previsionales. Las AFP se encargan también del pago de pensiones bajo la modalidad de retiros programados ${ }^{2}$, mientras que de la modalidad de las rentas vitalicias ${ }^{3}$ se ocupan las compañías de seguros de vida.

El objetivo principal de todo sistema de pensiones es asegurar un ingreso estable a los trabajadores cuando concluyen su vida laboral, esperando que dicho ingreso se corresponda a aquellos que percibió durante su vida activa. El sistema antiguo basado en el reparto otorga tasas de reemplazo del orden del $70 \%$ a quienes cumplen los requisitos ${ }^{4}$. El actual sistema presenta una serie de ventajas con respecto al sistema del reparto; no obstante, este modelo no resuelve por sí sólo el financiamiento de la vejez en países con mala distribución del ingreso, como es el caso de Chile (Superintendencia de Pensiones, 2010).

Transcurridas tres décadas del sistema de capitalización individual se diagnosticó que había una gran parte de la población que no contaba con los ahorros suficientes para financiar en forma digna su vejez. Ello se explica por la baja densidad en las contribuciones por cotizaciones de los individuos (Superintendencia de Pensiones, 2006), así como por las diferencias de remuneraciones por género y otros factores. En 2008 se introdujo la principal reforma al sistema actual de pensiones, cuyo principal avance consistió en introducir un pilar solidario cuyo objetivo es la prevención de la pobreza y que se financia con impuestos generales (Superintendencia de Pensiones, 2010). Se trató de un avance, pero no fue suficiente. En 2015 se creó la Comisión Asesora Presidencial sobre el Sistema de Pensiones (CAPSP), a la que se encargó hacer un diagnóstico y formular propuestas de mejoras al sistema de pensiones. En el informe se indica que el $50 \%$ de los jubilados reciben pensiones inferiores

\footnotetext{
2 Véase [en línea] https://www.spensiones.cl/portal/institucional/594/w3-propertyvalue-9924.html\#faqs.

3 Véase [en línea] https://www.spensiones.cl/portal/institucional/594/w3-propertyvalue-9924.html\#faqs.

4 No se paga pensión a quienes contribuyeron al sistema durante menos de 15 años.
} 
a 82.650 pesos, con una brecha importante entre mujeres y hombres. La mediana de las pensiones de las mujeres es de 42.561 pesos, mientras que para los hombres es de 112.333 pesos. La mitad de los jubilados chilenos recibe como máximo un 34\% del promedio de su salario de los últimos diez años antes de entrar a la etapa pasiva. En este aspecto, el resultado anterior incluye a los jubilados con arreglo al sistema de pensiones previo a 1980. Así bien, se estima que aislando a los individuos del sistema de capitalización individual y tomando como horizonte a los pensionados en los años 2025 y 2035, la mitad de las personas no superarían el 37\% de las cifras antes mencionadas. Más aún, el valor anterior es extremadamente bajo en comparación con el promedio de la OCDE, equivalente a una tasa de reemplazo del $66 \%$.

Por último, y muy estrechamente relacionado con lo anterior, el 70\% de los chilenos opinan que los montos de las pensiones son insuficientes para costear un nivel de vida adecuado (OCDE, 2013). Esto motivó movilizaciones sociales en 2016 en demanda de cambios del modelo de pensiones para así optar a mejores beneficios (The Economist, 2016).

\section{Literatura sobre hipoteca inversa}

Una de las mayores disyuntivas que enfrentan los pensionados con respecto a su vivienda es si han de permanecer en ella, exponiéndose a una menor liquidez de la que se habían acostumbrado en su vida laboral, o bien vender el inmueble y destinar parte del dinero al pago de un arriendo, utilizando el monto excedente con el fin de aumentar sus ingresos (Bartel y Daly, 1980). Esta última opción es racional desde un punto de vista económico; sin embargo, arrendar y exponerse a cambios de propiedad conlleva importantes costos psicológicos (Davidoff, 2010). Una posible solución a tal problemática es la hipoteca inversa, también conocida como hipoteca reversa o hipoteca revertida. Se trata de un producto financiero que surgió en los Estados Unidos en los años ochenta y se ha expandido por distintas partes del mundo (hoy está presente también en el Canadá, Australia, España y el Japón, entre otros). Con dicho instrumento los pensionados y propietarios de viviendas pueden solicitar un préstamo usando su inmueble como colateral sin tener que abandonarlo.

Según Phillps y Gwin (1993) existen tres tipos principales de hipoteca inversa: la hipoteca conocida como hipoteca inversa a plazo (term reverse mortgage), que consiste en pagos de suma fija por un período determinado después de concluido el cual se reembolsa el préstamo vendiendo la propiedad; la hipoteca inversa con plazo dividido (split-term reverse mortgage), que emula las condiciones precedentes, pero con la diferencia de que en esta las personas continúan viviendo en su hogar luego de terminados los pagos y el préstamo se reembolsa solo cuando el prestatario fallece, se muda o vende la propiedad; por último está la hipoteca con plan de pagos mensuales (tenure reverse mortgage), considerablemente más utilizada que las anteriores y que consiste en pagos de suma fija hasta que el individuo fallece, se muda o vende la propiedad, en la que el monto del préstamo depende positivamente de la edad del prestatario junto con el valor de la propiedad, y negativamente de la tasa de interés (Fornero, Rossi y Urzi, 2016).

Se argumenta que los individuos que adquieren una hipoteca inversa son personas mayores ricas pero pobres en dinero en efectivo, es decir, personas de edad dueñas de una considerable riqueza (representada por el elevado valor de su inmueble) pero con restricciones de liquidez (Moulton y otros, 2015). En este sentido, Nakajima y Telyukova (2017) analizan que las características preponderantes para la toma del instrumento son tener ingresos bajos, poseer un inmueble caro, no tener una hipoteca pendiente, estar solo y padecer de mala salud.

Por su parte, antes de poner en práctica la hipoteca inversa se realizaron simulaciones en distintos países a fin de determinar su potencialidad. Los resultados al respecto han sido diversos. 
Uno de los estudios más pertinentes en relación con las simulaciones es el de Mayer y Simons (1994), realizado en etapas iniciales de la aplicación de la hipoteca inversa en los Estados Unidos. En ese estudio, los autores señalan que la contratación de una hipoteca inversa permitiría reducir cerca de tres cuartas partes de la pobreza en el grupo objetivo. Los autores proceden a convertir el valor de la propiedad en anualidades con periodicidad de pago mensual (tenure). Así bien, por falta de datos y metodologías avanzadas, se realizan supuestos arbitrarios en lo referente al valor de las propiedades y el coeficiente préstamo-valor. Esta última variable es la más criticable, pues corresponde al porcentaje del inmueble que los individuos pueden utilizar como colateral. Los autores la fijan en un $75 \%$, siendo que en estudios posteriores esta se obtiene matemáticamente, lo que da lugar a valores menores.

Kutty (1998) realiza su estudio post implementación de la hipoteca inversa en los Estados Unidos. Con arreglo a un instrumento de periodicidad de pago mensual, sostiene que si todo el grupo objetivo contratara una hipoteca inversa, menos de un tercio saldría de la pobreza. En el Reino Unido, Hancock (1998) realiza una simulación de la puesta en práctica de la hipoteca inversa siguiendo una metodología idéntica a la de Kutty (1998), y llega a la conclusión de que la reducción de la pobreza sería menor al 5\%. Estos resultados divergentes pueden ser parcialmente atribuidos a que en los Estados Unidos el instrumento no está sujeto a tributación mientras que en el Reino Unido sí, por lo que en este último caso los pagos se ven reducidos (Ong, 2008).

Moscarola y otros (2015) analizan el potencial social de la implementación de la hipoteca inversa en países europeos en los cuales aún no existe este instrumento. Los autores simulan cuánto se reduciría la pobreza en el grupo objetivo tomando en consideración tres escenarios con tasas de descuento arbitrarias y dos escenarios con distintos porcentajes de uso del inmueble como colateral. España y Bélgica son los países con mayor potencial, con una reducción de pobreza máxima cercana al 25\%. Por su parte, Francia e Italia podrían alcanzar cifras de disminución de más del 10\%, mientras que en los demás países analizados (Suiza, Austria, Holanda, Alemania y Dinamarca) la reducción sería menor.

En Chile, Muñoz (2011) señala que si todo el grupo objetivo contratara la hipoteca inversa, la pobreza se reduciría en un 88\%. Sin embargo, este autor no considera una modalidad de periodicidad de pago mensual, sino un plazo dividido (split term). Además, el estudio no analiza la mayor liquidez otorgada por el instrumento en términos per cápita, como en la mayoría de los estudios internacionales, ni tampoco incluye una desagregación de los resultados en distintos grupos de interés. Fuentes y Moris (2014) examinan la factibilidad legal de la implementación de la hipoteca inversa en Chile, concluyendo que existe un panorama propicio, dado que el entorno jurídico vigente permite la efectiva configuración del contrato, existiendo además mecanismos legales idóneos que brindan protección a las partes.

Nuestro artículo se basa en la metodología utilizada por Ma y Deng (2013) y Wang y Kim (2014), quienes introducen el principio de la fijación de los precios de los seguros. Este principio consiste en realizar una simulación en la que se evitan utilidades negativas para el prestamista, considerando el hecho de que los pagos al prestatario podrían superar el precio de la vivienda en un momento dado, como cuando la apreciación de la vivienda sea menor a la esperada o el contratante viva más de lo estimado: se estaría así tomando en cuenta la relación entre un seguro de garantía y las posibles pérdidas que podría sufrir el prestamista. En los estudios anteriores no se había incluido esta interconexión, por lo que se restaba importancia a la relación descrita. Por lo tanto, al permitir que la institución financiera defina los pagos mensuales en el punto de equilibrio donde los valores esperados de los seguros recibidos sean equivalentes al valor esperado de las pérdidas, se logra que los pagos se ajusten más a la realidad, lo cual resulta fundamental para motivar a las instituciones financieras a participar en este tipo de mercado. No obstante, el método de simulación de estos autores no ha sido aplicado con el objetivo de analizar el impacto social de la hipoteca inversa, por lo que el presente estudio será pionero en este aspecto. 
Por último, más allá de la potencialidad teórica del instrumento, pasadas tres décadas desde su creación, su implementación y uso se encuentran por debajo de lo esperado (Davidoff, Gerhard y Post, 2017). En efecto, en los Estados Unidos en 2011 este producto financiero fue utilizado por solo el 2,1\% del total de las personas que podrían hacerlo: se trata del porcentaje más alto obtenido hasta la fecha (Nakajima y Telyukova, 2017). Davidoff, Gerhard y Post (2017) sostienen que esa cifra se debe a que los grupos objetivo no entienden bien el instrumento. Lo anterior se complementa con el estudio de Moulton y otros (2015), quienes afirman que la hipoteca inversa tiene una reducida tasa de uso debido a que las personas de edad tienen aversión a los instrumentos financieros complejos o bien no entienden a cabalidad lo que se les está ofreciendo.

\section{Metodología y datos}

\section{Marco analítico}

A fin de calcular las rentas mensuales se utilizará una hipoteca inversa de periodicidad de pago mensual, que se encuentra ampliamente documentada y nos brinda una plataforma confiable donde comparar los resultados obtenidos. Luego se procede con arreglo a Ma y Deng (2013) y a Wang y Kim (2014), en que dichos pagos mensuales se calculan utilizando el precio del inmueble de los individuos al entrar en vigor el contrato. Se establece un precio arbitrario del inmueble a efectos de evidenciar cómo cambian los pagos mensuales si el contratante toma una hipoteca inversa en distintos tramos etarios, teniendo en cuenta el mismo valor de la propiedad. En nuestro estudio seguimos este mismo proceso, pero utilizamos el valor real de la vivienda que usarían como colateral los individuos.

Para referenciar los precios de las viviendas se utilizó la Encuesta de Protección Social (EPS) 2009, que es representativa a nivel poblacional y cuenta con información detallada y ratificada de los pensionados, que es el grupo de interés. No obstante lo anterior, el modelo requiere obtener el valor del inmueble al momento de la jubilación de cada individuo. Para esto se utiliza la simulación de Ma y Deng (2013) y Wang y Kim (2014), agregando un nivel previo para la obtención de esta variable utilizando los valores correspondientes a 2009 para cada persona. Por otro lado, el presente estudio presenta la metodología de estos autores en cuanto a los pagos mensuales, incorporando en extenso el uso de las tablas de mortalidad (Superintendencia de Pensiones, 2009a).

El algoritmo utilizado para simular los pagos mensuales tiene en cuenta lo siguiente:

i) el precio de la vivienda imputado en la EPS 2009;

ii) la determinación del precio de la vivienda a la edad de jubilación;

iii) la determinación del precio de la vivienda al término del contrato;

iv) la determinación de la relación préstamo-valor, y

v) la determinación de los pagos mensuales (utilizando las tablas de mortalidad).

La modelación comienza con el precio de vivienda imputado a 2009 como variable base, cuya obtención se explica en el apartado IV.3. Luego se procede de la siguiente manera:

a) A partir del precio de la vivienda imputado a 2009 para el individuo $i,\left(P_{2009, i}\right)$, para cada persona se estima el precio de vivienda al momento de jubilarse $\left(P_{J, i}\right)$, el cual se basa en la metodología expuesta por Szymanoski (1994). Véase una descripción de esta metodología en el anexo A1.

$$
P_{J, i}=\frac{P_{2009, i}}{\exp \left(\mu \cdot t_{i}+0,5 \cdot \sigma^{2} \cdot t_{i}\right)}
$$


Donde $\mu$ corresponde al índice promedio del crecimiento anual del precio de venta de los inmuebles (Banco Central de Chile) en la economía y $\sigma^{2}$ representa la varianza del mismo índice de crecimiento, mientras que $t_{i}$ señala los años transcurridos desde la jubilación del individuo $i$ hasta 2009, según la información extraída de la EPS 2009.

b) Luego de obtenido el precio de vivienda al jubilarse se estima el precio de vivienda al término del contrato $\left(P_{T, i}\right)$, aproximable al precio del inmueble cuando el individuo $i$ cumple su expectativa de vida (con arreglo a Szymanoski, 1994).

$$
P_{T, i}=P_{J, i} \cdot \exp \left(\mu \cdot T_{i}+0,5 \cdot \sigma^{2} \cdot T_{i}\right)=\frac{P_{2009, i} \cdot \exp \left(\mu \cdot T_{i}+0,5 \cdot \sigma^{2} \cdot T_{i}\right)}{\exp \left(\mu \cdot t_{i}+0,5 \cdot \sigma^{2} \cdot t_{i}\right)}
$$

En este caso $T_{i}$ representa el valor esperado de la duración del contrato en años, es decir, la esperanza de vida de $i$, menos la edad de jubilación, la que se obtiene combinando la información del Instituto Nacional de Estadística (2010a) y las tablas de mortalidad disponibles en la Superintendencia de Pensiones. A su vez, los valores de la esperanza de vida como la edad de jubilación dependerán del género del individuo.

c) Se obtiene la relación préstamo-valor (RPV), que corresponde al porcentaje máximo que el individuo puede usar como colateral del precio de vivienda al jubilarse, lo que se describe en la ecuación (3).

$$
R P V_{i}=\frac{P_{T, i} /(1+r)^{T_{i}}}{P_{J, i}}
$$

Donde $r$ representa la tasa de descuento del préstamo, la cual se compone de la suma lineal de la tasa de interés libre de riesgo ${ }^{5}$ de la economía $\left(i_{i r}\right)$, la tasa de seguro de garantía mensual $^{6}\left(T S G_{m}\right)$ y el margen del prestamista ${ }^{7}(M P)$. Estos componen los elementos que caracterizaran a la economía nacional.

d) Se calcula el valor presente del préstamo (VPP), que puede entenderse como el monto que financia la institución financiera en caso de que solo se realice un pago de suma alzada al momento de firmar el contrato, tal como se describe en la ecuación (4), donde se incluye la tasa de seguro de garantía inicial ${ }^{8}$ del contrato $\left(T S G_{0}\right)$

$$
V P P_{i}=P_{J, i} \cdot\left(R P V_{i}-T S G_{0}\right)
$$

e) Con arreglo a Wang y Kim (2014), se determinan los pagos mensuales de acuerdo a la ecuación (5), donde $\tau_{i}$ representa el valor esperado de la duración del contrato en meses.

$$
P M_{i}=\frac{V P P_{i}}{\sum_{n=0}^{n=\left(\tau_{i}-1\right)}(1+r)^{-n}}
$$

\footnotetext{
5 Media mensual de la tasa de interés del mercado secundario de los bonos licitados por el Banco Central de Chile (BCP) a 10 años en 2009 (véase en línea]https://si3.bcentral.cl/Boletin/secure/boletin.aspx?idCanasta=1MRMW2951).

6 Se utiliza la tasa del 0,5\% vigente en el mercado estadounidense (Rodda y otros, 2003). La misma tasa se utiliza en los artículos acerca de la metodología seguida (Wang y Kim2014; Ma y Deng, 2013).

7 Variable que varía normalmente entre el $1 \%$ y el $2 \%$ (Rodda, Herbert y Lam, 2000). Se utiliza el $1 \%$ siguiendo a Wang y $\operatorname{Kim}$ (2014).

8 Se utiliza la tasa del $2 \%$ vigente en el mercado estadounidense (Rodda y otros, 2003). La misma tasa se utiliza en el artículo acerca de la metodología seguida (Wang y Kim, 2014).
} 
La ecuación (5) proporciona el monto para los pagos mensuales en el supuesto de que todos los individuos vivan la cantidad de años que se indica en su esperanza de vida. Sin embargo, esto puede resultar poco realista, ya que en la práctica los individuos pueden fallecer antes o después de esa fecha. Esto nos podría dar una idea equivocada acerca de los pagos mensuales, por lo que, y con el propósito de mejorar los alcances de la simulación, extenderemos la ecuación (5) incluyendo un factor de descuento que considere la probabilidad de que $i$ se encuentre vivo para recibir el pago en el mes $N,\left(p_{N, i}\right)$, siempre que estuviera vivo al momento de contratar la hipoteca inversa, tal como se expresa en la ecuación (6).

$$
P M_{i}=\frac{V P P_{i}}{\sum_{N=0}^{N=T}\left[(1+r)^{-N} \cdot\left(p_{N, i}\right)\right]}
$$

Donde el término $T$ simboliza el período en el que la probabilidad de sobrevivencia alcance el valor de 0 .

Un aspecto importante a tener en cuenta respecto a la ecuación (6) es que en el presente estudio $p_{N, i}$ se obtendrá a través de las tablas de mortalidad del sistema de pensiones de Chile a 2009 (véase el anexo A2), donde la probabilidad de fallecer se presenta de forma anual y no mensual como requiere la modelación. Por ese motivo, supondremos que la probabilidad de que un individuo esté vivo en un año determinado será igual a la probabilidad de que el mismo individuo viva en cada mes dentro de ese año. Por otro lado, las tablas de mortalidad del sistema de pensiones de Chile al 2009 también determinan el valor límite $T$ (110 años para ambos géneros). Así bien, esto corresponde al mes $T=540$ de duración del contrato para un individuo que se jubile a los 65 años y mes $T=600$ para un individuo que se jubile a los 60 años.

\section{Parámetros de la economía}

La modelación requiere conocer parámetros específicos de la economía chilena, a saber:

\section{Tasa de descuento de la hipoteca inversa}

En la literatura especializada la tasa de descuento que se utiliza para el cálculo de los pagos por concepto de hipoteca inversa se obtiene como la suma de una tasa libre de riesgo, generalmente a diez años, más un diferencial por concepto de margen al prestamista y otro para cancelar un seguro de garantía mensual que se paga a lo largo de la duración del préstamo. Luego, se considera como tasa libre de riesgo del Banco Central de Chile a diez años en pesos (BCP-10), cuyo promedio anual en 2009 era del 5,67\%. A su vez, el margen al prestamista y seguro de garantía mensual serán del 1\% y el 0,5\% en tasas anuales (Rodda, Hebbert y Lam, 2000), respectivamente. Los valores anteriores son los utilizados en la hipoteca inversa en los Estados Unidos.

\section{Costo inicial del préstamo}

Dicho costo corresponde al precio del inmueble al momento de contratar el instrumento, multiplicado por una tasa de garantía inicial del 2\% (utilizada en Ma y Deng (2013) y en Wang y Kim (2014)). 


\section{Media y desviación estándar del cambio porcentual del precio de las viviendas}

Las variables con respecto al movimiento en el precio de las viviendas se obtienen utilizando el índice del precio de inmuebles provisto por el Banco Central de Chile, disponible desde 2003 a 2014. Así bien, se utiliza la media simple del cambio en el índice anual y su desviación estándar en todo este periodo. Las cifras anteriores fueron del $4,4 \%$ y el $2,9 \%$, respectivamente.

\section{Esperanza de vida y tablas de mortalidad}

Para determinar la esperanza de vida de los individuos de nuestra muestra se utiliza la tabla de mortalidad de Chile al 2009. Los valores para la esperanza del horizonte de vida son de 76 años para los hombres y 81 años para las mujeres (INE, 2010b). Por su parte, para determinar las probabilidades de supervivencia de los individuos en los años en que está vigente el contrato se utilizan las tablas de mortalidad para pensiones de renta vitalicia en Chile a 2009, diferenciadas por género. Las tablas de mortalidad figuran en el anexo A2.

Existen diferencias por género en torno a la probabilidad de sobrevivencia. Se muestran las probabilidades de sobrevivencia de hombres que se jubilan a los 65 años y de mujeres que se jubilan a los 60 y 65 años, considerando los 110 años como edad límite para ambos géneros, de forma que a cada edad los hombres tienen una menor probabilidad de estar vivos, en comparación con las mujeres, lo cual se magnifica en las edades medias del tramo de vida analizado (véase el gráfico 1).

\section{Gráfico 1}

Probabilidad de sobrevivencia por sexo y edad de jubilación (En porcentajes)

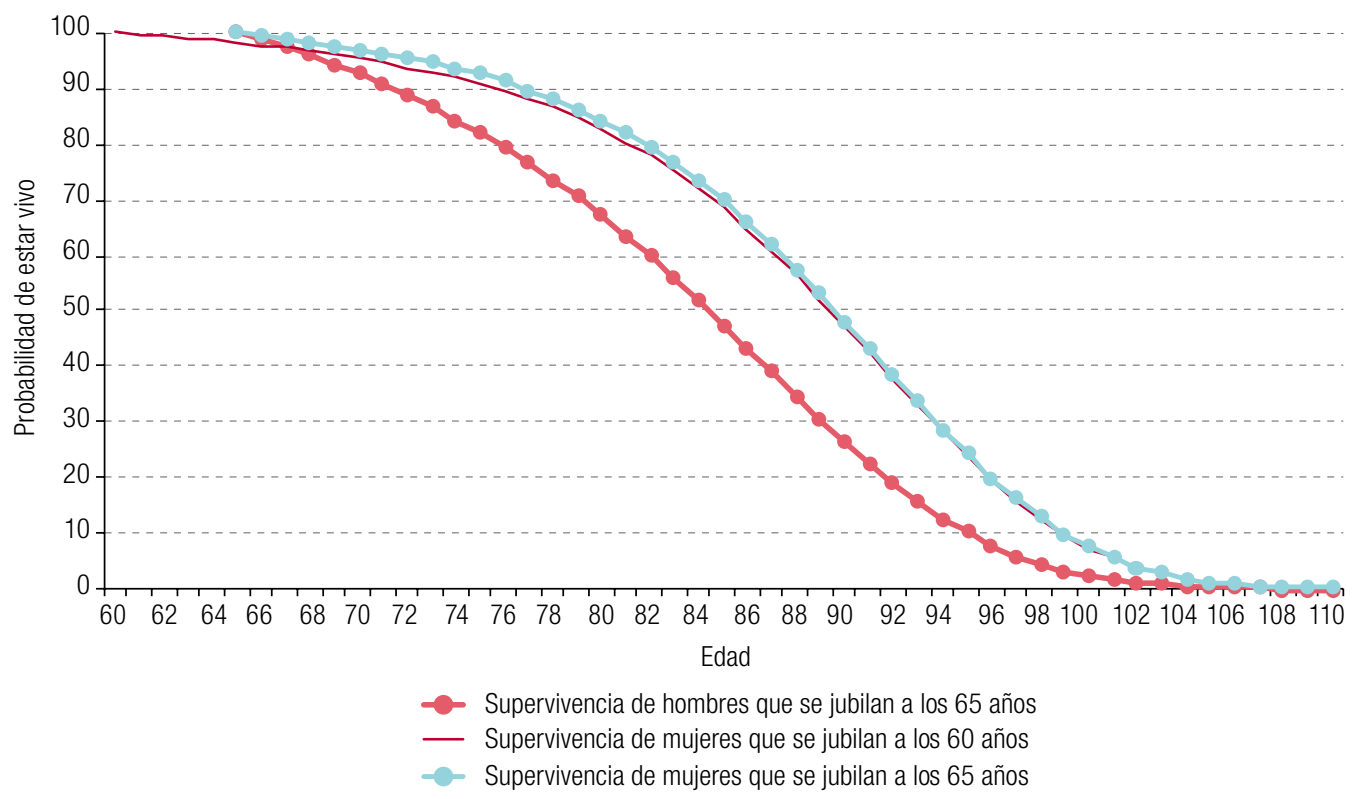

Fuente: Elaboración propia, sobre la base de Superintendencia de Pensiones de Chile, "Compendio de Normas del Sistema de Pensiones, Libro III, Título X, Tablas de Mortalidad, Anexo № 5”, Santiago, 2009 [en línea] http://www.spensiones.cl/ portal/compendio/596/w3-propertyvalue-4350.html. 


\section{Datos}

La Encuesta de Protección Social (EPS) es una encuesta longitudinal con representatividad a nivel poblacional que en su versión 2009 recoge observaciones de diversa índole sobre cerca de 16.000 hogares de todo Chile. La EPS ha sido fundamental para el análisis y diseño de políticas públicas en Chile ${ }^{9}$, específicamente en lo relacionado con las pensiones, por lo que resulta una fuente de información fundamental para nuestro estudio. A partir de ella, se extrajo una muestra en la que se conserva solo el grupo objetivo de la hipoteca inversa, es decir, los individuos propietarios de una vivienda en edad de jubilación (mujeres de 60 años o más, y hombres de 65 años o más).

Consecuentemente, a fin de obtener el precio de las viviendas al momento de tomar la encuesta se formula la siguiente pregunta: "Si vendiera hoy su casa, ¿cuánto cree que sería el valor de esta propiedad?"10. A la respuesta a esa pregunta llamaremos de ahora en adelante "precio de la vivienda". Sin embargo, al ser esta una apreciación personal, puede estar sesgada. Con el propósito de corregir este sesgo se asumirá que la movilidad de individuos entre regiones es baja, por lo que se segmentará a los individuos según la región donde nacieron y por deciles según factor de expansión, formando grupos homogéneos en cuanto al inmueble. Así bien, a cada individuo se le imputa como precio de su vivienda el promedio de la valoración de su segmento correspondiente. Esto resuelve el posible sesgo y, además, se recuperan las observaciones de los individuos que no saben o no responden cuando se les consulta por el precio de su vivienda. Por otro lado, en la muestra el valor de las viviendas no se distribuye en forma normal. Lo anterior se corrige recortando los datos de precios de vivienda sobre el percentil 97,5, que corresponde a precios de vivienda superiores a 100 millones de pesos. La distribución resultante queda representada por el gráfico 2. A su vez, el cuadro 1 incluye lo anterior y muestra la comparación entre las variables de precio de vivienda y precio de vivienda imputado, que corresponde al valor de la casa con los arreglos enunciados ya aplicados.

\section{Gráfico 2}

Distribución de precios de las viviendas en Chile

(En porcentajes)

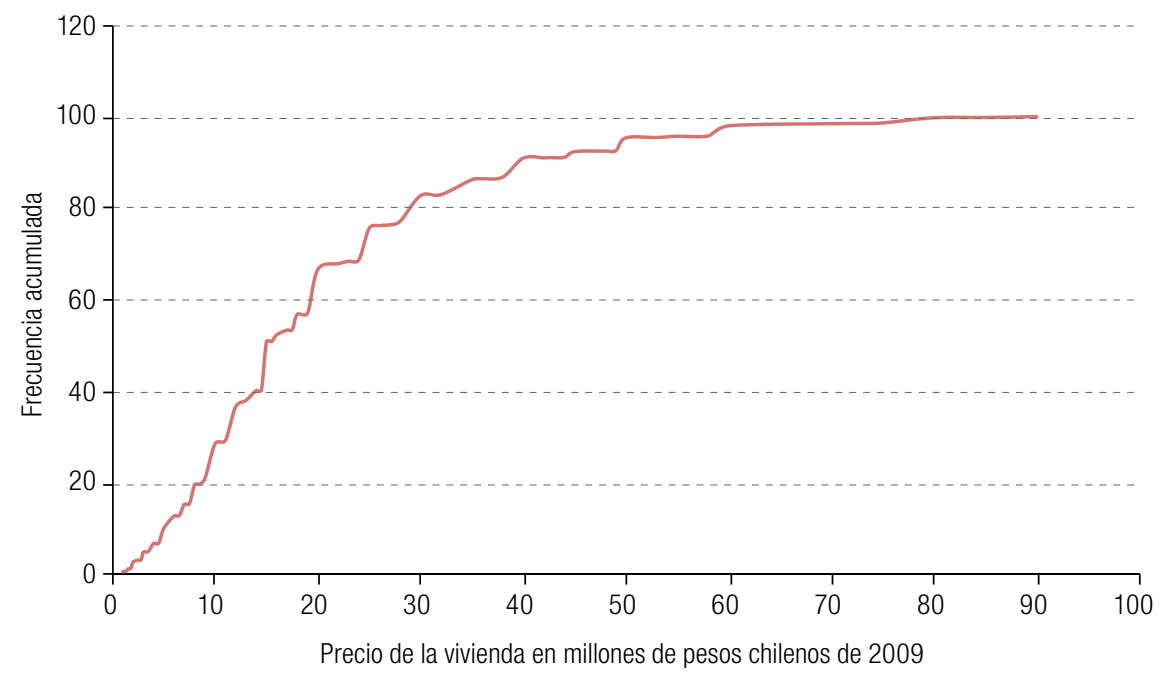

Fuente: Elaboración propia, sobre la base de la Encuesta de Protección Social, 2009.

\footnotetext{
9 A través de ella la Comisión Asesora Presidencial Sobre el Sistema de Pensiones (2015) detectó falencias en esta temática.

10 Esta pregunta corresponde a la consulta d17 de la EPS 2009.
} 
Cuadro 1

Comparación precio-vivienda y precio-vivienda imputado

\begin{tabular}{lccccc}
\hline Variable & Observaciones & Media & $\begin{array}{c}\text { Desviación } \\
\text { estándar }\end{array}$ & Mínimo & Máximo \\
\hline Precio vivienda (en millones de pesos de 2009) & 1752 & 20,60 & 15,00 & 1,00 & 90,00 \\
\hline Precio vivienda imputado (en millones de pesos de 2009) & 2627 & 20,40 & 4,11 & 2,50 & 50,00 \\
\hline
\end{tabular}

Fuente: Elaboración propia usando Encuesta de Protección Social 2009.

Nota: Cuadro elaborado en base a 2.627 observaciones que representan a una población de 1.623 .326 individuos.

Finalmente, de este proceso se conservaron 2.627 observaciones, que representan una población de 1.623 .326 hogares compuesta por un 59,1\% de mujeres y una edad promedio de 71 años. De los encuestados, el 65\% corresponde a jefes de hogar con un ingreso promedio por hogar de 103.749 pesos. Por otro lado, el promedio del ingreso per cápita resultó ser de 34.724 pesos (véase el cuadro del anexo A3) y, dado lo anterior, el $86,25 \%$ de las personas se encuentran bajo la línea de pobreza ${ }^{11}$.

\section{Sección empírica}

Para hacer una simulación de los pagos mensuales es preciso conocer el precio de las viviendas al momento de jubilarse y al terminar el contrato, el precio inicial de la vivienda imputado a 2009 en la EPS, siguiendo la modelación de Szymanoski (1994). Se advierte una media de 14 millones de pesos en el precio de los inmuebles al momento de la jubilación y una media levemente superior a 30 millones de pesos para la esperanza del valor de las propiedades al terminar el contrato (véase el cuadro 2). De lo anterior se puede obtener la relación préstamo-valor (RPV). Se observa que la media es del $59,42 \%$. Además, se puede subdividir este valor por género, donde la RPV para las mujeres es del $53,92 \%$ y para los hombres del $72,36 \%$. Las cifras anteriores concuerdan con el hecho de que la esperanza de la duración del contrato para los hombres es menor, debido a una mayor edad de jubilación y menor esperanza de vida que las mujeres.

Una vez obtenida la RPV podemos calcular el valor presente del préstamo (VPP), que se puede entender como una suma alzada que la institución financiera pagaría al dueño del inmueble al momento de contratar la hipoteca inversa, en vez de efectuar pagos mensuales. La media del VPP es de 8 millones de pesos, a partir de la cual se calculan los pagos mensuales suponiendo que todos los individuos aplicables contraten una hipoteca inversa, observando que la media de dichos pagos es de 62.508 pesos, con una desviación estándar de 29.760 pesos. Sin embargo, al considerar en la muestra a los pensionados autónomos ${ }^{12}$, la pensión promedio resulta ser igual a 145.808 pesos, valor que se vería incrementado en un $43 \%$ si incluyéramos los pagos por la hipoteca inversa. Ahora bien, si consideramos en la muestra a los pensionados bajo aporte solidario (no autónomo), la pensión promedio ascendió a 58.245 pesos, cifra que se vería incrementada en un 107\% si tuviéramos en cuenta los pagos de la hipoteca inversa. Estos incrementos tan grandes se explican por lo bajo de las pensiones en Chile, pero también ponen de manifiesto que las personas mayores poseen importantes volúmenes de riqueza ilíquida.

También procede hacer un análisis de los pagos de la hipoteca inversa según el género del pensionado, ya que este condiciona la edad de jubilación y la esperanza de vida, elementos que determinan la duración del contrato y el monto del préstamo al cual podrían acceder. Por otro lado,

\footnotetext{
${ }^{11}$ Línea de pobreza urbana en términos de situación de pobreza por ingresos (absoluta) para Chile (véase [en línea] http:// observatorio.ministeriodesarrollosocial.gob.cl/casen/casen_def_pobreza.php), que corresponde a 64.134 pesos per cápita.

12 Es decir, sin considerar aportes estatales. 1.093 (41\% de la muestra) observaciones presentan esta característica.
} 
el género también condiciona el monto de la pensión base, lo que a su vez define la base inicial de la riqueza, ya que las mujeres reciben en promedio una pensión de 51.174 pesos mientras que los hombres reciben en promedio 89.185 pesos (véase el cuadro 2). Ello se explica por diferencia en la participación laboral y por las brechas salariales entre mujeres y hombres existentes en Chile (Sáez, 2010).

Cuadro 2

Estimación de los parámetros de la hipoteca inversa

\begin{tabular}{lcrrrr}
\hline Variable & Observaciones & Media & $\begin{array}{c}\text { Desviación } \\
\text { estándar }\end{array}$ & Mínimo & Máximo \\
\hline Precio de la vivienda al jubilarse (en millones de pesos de 2009) & 2627 & 14,00 & 5,40 & 1,12 & 47,80 \\
\hline $\begin{array}{l}\text { Precio de la vivienda al término del contrato } \\
\text { (en millones de pesos de 2009) }\end{array}$ & 2627 & 31,6 & 13,60 & 1,83 & 122,00 \\
\hline Relación préstamo-valor (en porcentajes) & 2627 & 59,42 & 8,44 & 53,92 & 72,36 \\
\hline Valor presente del préstamo (en millones de pesos de 2009) & 2627 & 8,07 & 3,43 & 0,79 & 33,10 \\
\hline Pagos mensuales (en pesos) & 2627 & 62508 & 29760 & 6807 & 285512 \\
\hline Pagos mensuales de las mujeres (en pesos) & 1552 & 51174 & 20539 & 7883 & 178732 \\
\hline Pagos mensuales de los hombres (en pesos) & 1075 & 89158 & 31053 & 6807 & 285512 \\
\hline
\end{tabular}

Fuente: Elaboración propia usando Encuesta de Protección Social 2009.

Nota: Cuadro elaborado en base a 2.627 observaciones que representan a una población de 1.623.326 individuos.

Como hemos señalado, la edad de jubilación es distinta entre mujeres y hombres, con una diferencia de cinco años, lo cual afecta la forma en que se desempeñará el contrato de la hipoteca inversa, ya que condiciona su duración. Actualmente en Chile las mujeres se jubilan a los 60 años de edad, lo que estudiaremos como el escenario estándar, aunque también hemos analizado un escenario alternativo en el que las mujeres se jubilan a la misma edad que los hombres (65 años). Tal y como se esperaba, al aumentar las edad de jubilación de las mujeres, el pago mensual de la hipoteca inversa aumenta en un 55\% (28.221 pesos); además, se reduce la brecha por género en un $74,3 \%$, tal como se puede apreciar en el cuadro 3. Por lo tanto, en igualdad de condiciones financieras existirá igualdad en el monto recibido por concepto de hipoteca inversa; si se desea utilizar este instrumento en el diseño de una política pública, esto ha de tomarse en cuenta.

Cuadro 3

Análisis de pagos mensuales según sexo y edad de jubilación

(En pesos chilenos)

\begin{tabular}{lccccc}
\hline Situación & $\begin{array}{c}\text { Edad de jubilación } \\
\text { mujeres }\end{array}$ & $\begin{array}{c}\text { Edad de jubilación } \\
\text { hombres }\end{array}$ & $\begin{array}{c}\text { Pagos mensuales } \\
\text { Total }\end{array}$ & $\begin{array}{c}\text { Pagos mensuales } \\
\text { mujeres }\end{array}$ & $\begin{array}{c}\text { Pagos mensuales } \\
\text { hombres }\end{array}$ \\
\hline Escenario estándar & 60 & 65 & 62508 & 51174 & 89158 \\
\hline Escenario alternativo & 65 & 65 & 82308 & 79395 & 89158 \\
\hline Variación & & & 19800 & 28221 & 0 \\
\hline
\end{tabular}

Fuente: Elaboración propia, sobre la base de la Encuesta de Protección Social, 2009.

Nota: Cuadro elaborado en base a 2.627 observaciones que representan a una población de 1.623.326 individuos.

Tomando los resultados anteriores sobre el escenario estándar, resulta útil agregar los pagos mensuales por concepto de este instrumento al ingreso familiar. La hipoteca inversa tiene la capacidad de aumentar, en promedio, cerca de un 60\% el ingreso del hogar del grupo objetivo, que pasaría de 103.749 pesos a 166.258 pesos. Consecuentemente, también se aumenta el ingreso per cápita en aproximadamente un 57\%, pasando de 34.724 pesos a 54.537 pesos, tal y como se observa en el cuadro 4. Esto no tiene solo connotación en la distribución de la riqueza, sino también en el aumento en la calidad de vida de estos hogares, debido a los mayores niveles de utilidad. 
Cuadro 4

Incidencia de la hipoteca inversa sobre el ingreso (escenario estándar) (En pesos chilenos)

\begin{tabular}{lcccr}
\hline Variable & Media & Desviación estándar & Mínimo & Máximo \\
\hline Ingreso del hogar sin contratar hipoteca inversa & 103749 & 136576 & 0 & 2000000 \\
\hline Ingreso del hogar contratando hipoteca inversa & 166258 & 141879 & 7883 & 2121002 \\
\hline Media variación del ingreso del hogar & $60,25 \%$ & & & \\
\hline Ingreso per cápita sin contratar hipoteca inversa & 34724 & 49533 & 0 & 450000 \\
\hline Ingreso per cápita contratando hipoteca inversa & 54537 & 57525 & 2037 & 519441 \\
\hline Media variación del ingreso per cápita & $57,06 \%$ & & & \\
\hline
\end{tabular}

Fuente: Elaboración propia usando EPS 2009.

Nota: Cuadro elaborado en base a 2.627 observaciones que representan a una población de 1.623 .326 individuos.

Tras haber simulado los pagos mensuales y suponiendo que todos los individuos que están en condiciones de hacerlo contratan una hipoteca inversa, es posible analizar qué consecuencias tiene esto sobre la pobreza en la muestra. Se observa que la contratación de este instrumento provocaría una reducción del 15\% en el índice de pobreza para toda la muestra (véase el cuadro 5).

Cuadro 5

Efecto potencial de la hipoteca inversa sobre la pobreza (escenario estándar)

(En porcentajes, salvo la columna de cifras de la izquierda)

\begin{tabular}{lcccc}
\hline \multirow{2}{*}{ Variable } & \multirow{2}{*}{ Observaciones } & \multicolumn{2}{c}{ Índice de pobreza } & Reducción porcentual \\
\cline { 3 - 4 } & 2627 & Sin hipoteca inversa & Con hipoteca inversa & de la pobreza \\
\hline Total & 434 & 86,25 & 73,17 & 15,17 \\
\hline $\begin{array}{l}\text { Cotizantes a Administradoras de } \\
\text { Fondos de Pensiones (AFP) }\end{array}$ & 1935 & 90,71 & 83,77 & 7,65 \\
\hline Encuestado es jefe del hogar & 692 & 81,30 & 65,24 & 19,75 \\
\hline Encuestado no es jefe del hogar & 1552 & 95,48 & 87,95 & 7,89 \\
\hline Mujeres & 1075 & 88,40 & 79,64 & 9,91 \\
\hline Hombres & & 81,18 & 57,94 & 28,63 \\
\hline
\end{tabular}

Fuente: Elaboración propia sobre la base de la Encuesta de Protección Social, 2009.

Nota: Cuadro elaborado en base a 2.627 observaciones que representan a una población de 1.623 .326 individuos.

En este sentido, el efecto potencial es bajo en comparación con los estudios realizados en los Estados Unidos (Mayer y Simons, 1994; Kutty, 1998), España y Bélgica (Moscarola y otros, 2015), aunque mayor que el detectado en el Reino Unido (Hancock, 1998), Dinamarca, Alemania, Holanda, Austria y Suecia (Moscarola y otros, 2015). La reducción de la pobreza que mostró nuestra simulación se encuentra entre los niveles alcanzados para Italia y Francia (Moscarola y otros, 2015), tal como se observa en el cuadro 6 . Esto nos indica que nuestro modelo de simulación es confiable, ya que la predicción de la reducción de la pobreza está dentro de los rangos definidos en la literatura especializada, lo que también confirma la veracidad de los parámetros económicos establecidos. 


\section{Cuadro 6}

Efecto potencial de la hipoteca inversa sobre la pobreza en distintos países (En porcentajes)

\begin{tabular}{lccl}
\hline País & Porcentaje de reducción de pobreza & Año de los datos & Autor \\
\hline Suecia & 3 & 2012 & Moscarola y otros, 2015 \\
\hline Reino Unido & 4 & 1995 & Hancock, 1998 \\
\hline Austria & 4 & 2012 & Moscarola y otros, 2015 \\
\hline Holanda & 5 & 2012 & Moscarola y otros, 2015 \\
\hline Alemania & 6 & 2012 & Moscarola y otros, 2015 \\
\hline Dinamarca & 8 & 2012 & Moscarola y otros, 2015 \\
\hline Francia & 14 & 2012 & Moscarola y otros, 2015 \\
\hline Italia & 16 & 2012 & Moscarola y otros, 2015 \\
\hline Bélgica & 25 & 2012 & Moscarola y otros, 2015 \\
\hline España & 27 & 2012 & Moscarola y otros, 2015 \\
\hline Estados Unidos & 29 & 1991 & Kutty, 1998 \\
\hline Estados Unidos & 74 & 1990 & Mayer y Simons, 1994 \\
\hline
\end{tabular}

Fuente: Elaboración propia.

a Los valores corresponden a la cota superior para cada país descrito en el documento.

Si se considera solamente a las personas pertenecientes al sistema de AFP, la reducción de pobreza es del 7,65\%, mucho menor que en el total de la muestra. Ello se debe a que, pese a que los cotizantes de AFP recibirían pagos mensuales por un valor un $20 \%$ mayor que el promedio de la muestra, sus ingresos iniciales son cerca de dos tercios de la media del total (véase el cuadro 5). Con respecto al jefe del hogar, la incidencia del instrumento en términos de reducción de pobreza es mayor a la media muestral y levemente más que el doble comparado con aquellos que no lo son, por lo que el impacto sería menor al inicialmente determinado, comparable al de Dinamarca y Alemania (Moscarola y otros, 2015). Aunque reducido, igual supone un impacto positivo en un poco más de 100.000 hogares.

Por último, es posible aislar el indicador con respecto al género. En mujeres la pobreza inicial es casi un 10\% mayor, dado ingresos per cápita 50\% más altos en hombres. Así bien, como se mostró en el cuadro 3, en el escenario estándar las mujeres reciben pagos ampliamente menores al de sus pares hombres por concepto de hipoteca inversa, a raíz de lo cual la reducción de pobreza es del $9,91 \%$, a diferencia del $28,63 \%$ en los hombres. Por lo tanto, si sumamos la hipoteca inversa a la decisión de jubilarse, se hace importante igualar las condiciones financieras por género, porque aunque su aporte mejorará el bienestar de las personas jubiladas y sus hogares, también podría acentuar las brechas en riqueza derivadas del género.

Al aumentar la edad de jubilación de las mujeres, el potencial social de este instrumento en ellas conlleva una reducción del $5,31 \%$, cifra superior a la situación estándar pero que continúa siendo menor al potencial del género masculino. Consecuentemente, la reducción porcentual de la pobreza en toda la muestra se amplía un 3,81\%. 


\section{Cuadro 7}

Potencial de la hipoteca inversa sobre la pobreza según el sexo y la edad de jubilación (En porcentajes en las tres columnas de la derecha)

\begin{tabular}{lccccc}
\hline Situación & $\begin{array}{c}\text { Edad de jubilación } \\
\text { de mujeres }\end{array}$ & $\begin{array}{c}\text { Edad de jubilación } \\
\text { de hombres }\end{array}$ & $\begin{array}{c}\text { Reducción porcentual } \\
\text { de la pobreza total }\end{array}$ & $\begin{array}{c}\text { Reducción porcentual } \\
\text { de la pobreza } \\
\text { de mujeres }\end{array}$ & $\begin{array}{c}\text { Reducción porcentual } \\
\text { de la pobreza } \\
\text { de hombres }\end{array}$ \\
\hline Escenario estándar & 60 & 65 & 15,17 & 9,91 & 28,63 \\
\hline Escenario alternativo & 65 & 65 & 18,98 & 15,22 & 28,63 \\
\hline Variación & & & 3,81 & 5,31 & 0,00 \\
\hline
\end{tabular}

Fuente: Elaboración propia sobre la base de la Encuesta de Protección Social 2009.

Nota: Cuadro elaborado en base a 2.627 observaciones que representan a una población de 1.623 .326 individuos.

Los resultados de nuestra simulación pueden parecer auspiciosos, pero se debe tener en cuenta que a ellos se llega suponiendo que todas las personas que pueden hacerlo contratan la hipoteca inversa, lo cual parece poco realista. En efecto, los resultados previstos en reducción de la pobreza a raíz de este instrumento no son los esperados. Davidoff, Gerhard y Post (2017) y Nakajima y Telyukova (2017) sostienen que solo el 1,7\% de los individuos con posibilidades de hacerlo en los Estados Unidos efectivamente contratan una hipoteca inversa, identificando además la participación en el instrumento de personas que están solas, tienen ingresos bajos, con mala salud y dueñas de propiedades más caras que el promedio. De esta manera, si nos concentramos solo en este grupo, es decir, el más participativo, en el presente estudio la reducción de pobreza sería cercana al 2\%. Ello se debe a que en dicho segmento los individuos son inicialmente tan pobres que los pagos mensuales no dan lugar a la superación de ese índice de vulnerabilidad para gran parte de estos contratantes, aunque sí aumentan su liquidez y, por ende, su nivel de bienestar. Sin embargo, se debe tener en cuenta que nuestros cálculos se limitan a las condiciones que observamos en el presente y, no lo que podrían darse en el futuro, como ingresos futuros, redes de apoyo familiar o potenciales subsidios.

\section{Análisis por tramo etario}

Nuestro análisis precedente parte del supuesto de que los individuos contratan la hipoteca inversa al momento de jubilarse, pero ellos pueden hacerlo cuando lo deseen a partir de la fecha de jubilación. Cabe señalar que a medida que aumenta la edad de la persona que celebra el contrato se producen efectos que inciden en los pagos mensuales. En primer lugar, contratar una hipoteca inversa a mayor edad disminuye la esperanza del número de períodos en que se efectúan los pagos, acrecentándolos. Esto, a su vez, reduce el descuento que se realiza en la relación préstamo-valor (RPV), aumentándola a medida que los individuos presentan un menor riesgo para el prestamista. Ambas consecuencias dan lugar a un alza en los pagos mensuales. Sin embargo, ello se ve contrarrestado por una menor apreciación de la propiedad, disminuyendo así la RPV.

Por su parte, en la literatura especializada se presenta una relación positiva entre la edad en que se contrata el instrumento y los pagos mensuales (Ma y Deng, 2013). El propósito de este apartado consiste entonces en simular cómo variarían los pagos mensuales a medida que un individuo representativo de distintos tramos etarios contrata una hipoteca inversa en Chile. Para ello se utiliza una tabla de mortalidad conjunta que no diferencia por género, que se detalla en el cuadro 11 del anexo 2.

Se presentan dos casos: en el primero (véase el cuadro 8 y el anexo) se considera que el precio de la vivienda al iniciar el contrato es el promedio de los precios de inmuebles al momento de jubilarse los individuos de la muestra, es decir 14 millones de pesos de 2009. En efecto, se analiza cómo variarían los pagos mensuales si un individuo representativo con este valor de inmueble contratara la hipoteca inversa a las edades de 65, 70, 75 y 80 años (véase el cuadro 8). 
Cuadro 8

Caso 1: análisis de la hipoteca inversa por tramo etario

\begin{tabular}{lrrrr}
\hline \multicolumn{7}{c}{ Precio del inmueble imputado de 14 millones de pesos de 2009 } & & & \\
\hline Edad al contratar hipoteca inversa & 65 & 70 & 75 & 80 \\
\hline Precio del inmueble imputado (en millones de pesos de 2009) & 14,00 & 14,00 & 14,00 & 14,00 \\
\hline Esperanza precio del inmueble al vencer el contrato (en millones de pesos de 2009) & 32,70 & 26,10 & 21,00 & 16,80 \\
\hline Relación préstamo-valor (en porcentajes) & 57,9 & 66,25 & 77,19 & 89,36 \\
\hline Valor presente del préstamo (en millones de pesos de 2009) & 7,73 & 8,99 & 10,50 & 12,20 \\
\hline Pagos mensuales (en pesos) & 62387 & 80179 & 107080 & 149793 \\
\hline
\end{tabular}

Fuente: Elaboración propia usando Encuesta de Protección Social 2009.

A medida que aumenta la edad de contratación disminuye el valor esperado del precio del inmueble al vencer el contrato, mientras que se amplía la RPV. Es decir, domina el efecto al alza sobre esta última variable. En vista de lo anterior, aumenta el valor presente del préstamo, el cual se ve potenciado por el menor número de períodos en que está vigente el contrato, incrementando así los pagos mensuales a tasas crecientes. Ello se aprecia claramente en el gráfico 3: los pagos mensuales, medios y marginales están en relación positiva con la edad de contratación. Un individuo representativo obtendría pagos mensuales periódicos de 62.387 pesos al contratar una hipoteca inversa a los 65 años, lo cual iría aumentando progresivamente hasta llegar a 149.796 pesos si opta por el instrumento a los 80 años. En el anexo A4 figuran más detalles acerca de los pagos.

Gráfico 3

Caso 1: pagos mensuales

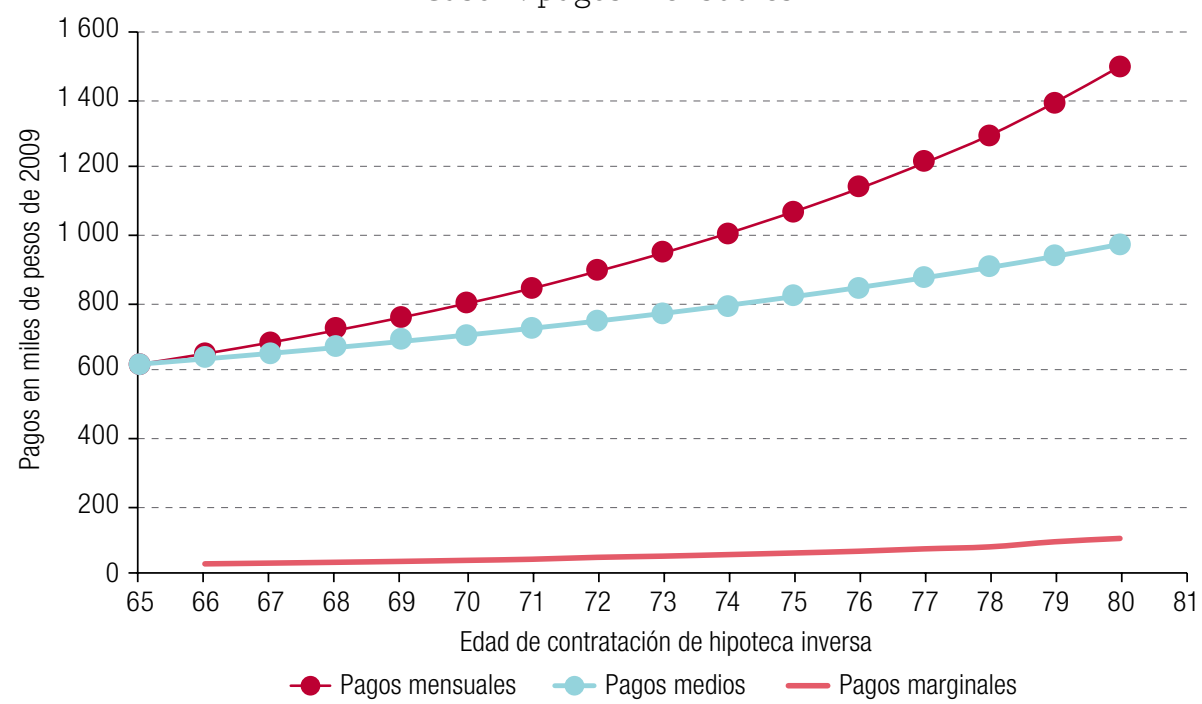

Fuente: Elaboración propia, sobre la base de la Encuesta de Protección Social, 2009

Por su parte, en el segundo caso (véase el cuadro 9 y el anexo) se sigue el procedimiento anterior, pero se considera que el precio inicial de la vivienda corresponde al promedio de los precios de inmuebles imputados a 2009, lo que equivale a 20,04 millones de pesos, manteniendo la relación préstamo valor en cada edad y las tasas de aumento de los pagos mensuales. En concreto, un individuo que se jubile a los 65 años obtendría otros 90.907 pesos mensuales por concepto de hipoteca inversa, cifra que iría en aumento hasta llegar a los 218.270 pesos si contrata la hipoteca inversa a los 80 años (véase el anexo A4). Entonces, al implementar este instrumento se observará dispersión en los pagos otorgados, debido a la distribución de la edad en que se realice el contrato. También incidirá la distribución del precio del inmueble, el cual dependerá de su futura plusvalía. 
Cuadro 9

Caso 2: análisis de hipoteca inversa por tramo etario

\begin{tabular}{lrrrr}
\hline \multicolumn{7}{c}{ Precio del inmueble imputado de 20,04 millones de pesos de 2009 } & & \\
\hline Edad al contratar hipoteca inversa & 65 & 70 & 75 & 80 \\
\hline Precio del inmueble imputado (en millones de pesos de 2009) & 20,04 & 20,04 & 20,04 & 20,04 \\
\hline Esperanza precio del inmueble al terminar el contrato (en millones de pesos de 2009) & 47,60 & 38,01 & 30,60 & 24,50 \\
\hline Relación préstamo-valor (en porcentajes) & 57,19 & 66,25 & 77,19 & 89,36 \\
\hline Valor presente del préstamo (en millones de pesos de 2009) & 11,30 & 13,10 & 15,3 & 17,80 \\
\hline Pagos mensuales (en pesos) & 90907 & 116832 & 156031 & 218270 \\
\hline
\end{tabular}

Fuente: Elaboración propia, sobre la base de la Encuesta de Protección Social, 2009.

Gráfico 4

Caso 2: pagos mensuales

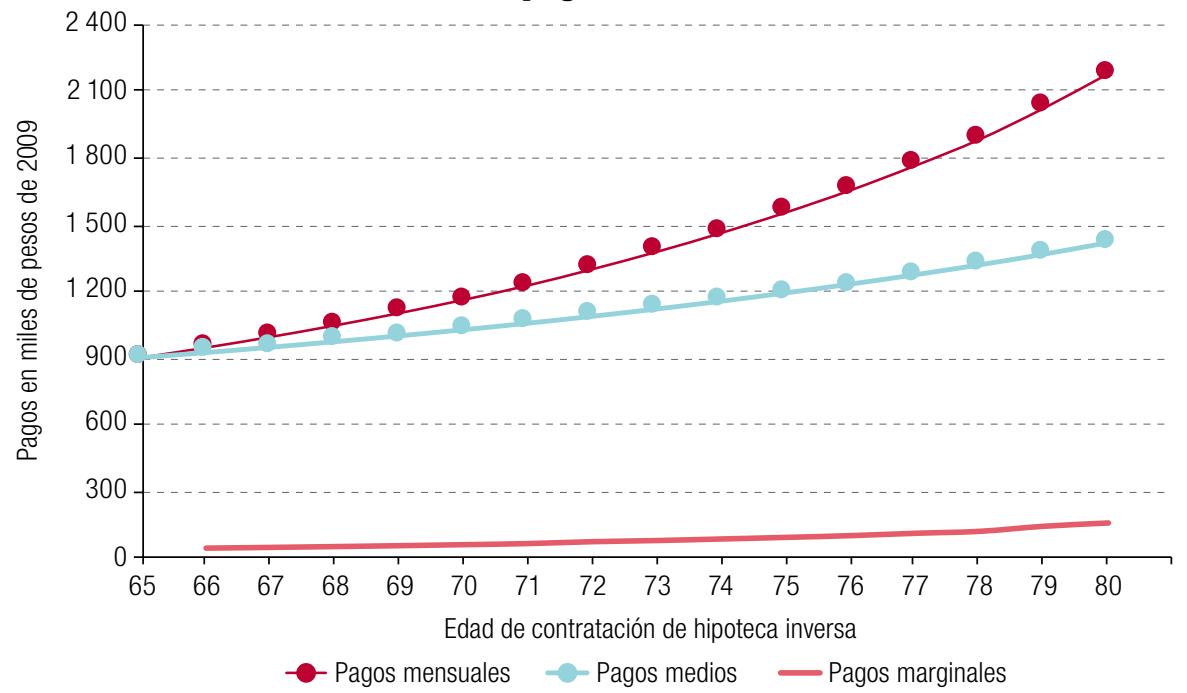

Fuente: Elaboración propia, sobre la base de la Encuesta de Protección Social, 2009.

\section{Conclusiones}

Nuestro estudio simuló el potencial social y económico de implementar la hipoteca inversa al grupo de pensionados en Chile. Utilizamos la metodología propuesta por Ma y Deng (2013) y Wang y Kim (2014), con algunas innovaciones como el uso de tablas de mortalidad de Chile, además de información del precio de las viviendas extraídas de la Encuesta de Protección Social, 2009, debido a su representatividad a nivel poblacional y carácter previsional. La muestra utilizada abarca a 1.623 .326 pensionados, que representan aproximadamente el 9\% de la población adulta en Chile (Superintendencia de Pensiones, 2009a). Implementar la hipoteca inversa no resuelve todos los problemas de ingreso que enfrentan las personas mayores en Chile, pero sí puede ayudar a aquellos que poseen una vivienda y que pueden utilizarla como colateral, a fin de mejorar su independencia económica al recuperar parte de un riqueza ilíquida.

Llegamos a la conclusión de que el aumento de liquidez a raíz de la contratación de una hipoteca inversa reduce el porcentaje de la población mayor de edad que se encuentra en situación de pobreza. En el caso de que todos los potenciales usuarios contraten una hipoteca inversa el índice de pobreza se reduciría en un 15\%, pero al restringir la muestra a las personas que pertenecen 
al sistema de pensiones vigente (capitalización individual), el índice de pobreza se reduce en un $7,65 \%$. Sin embargo, si nos limitamos a las características de los que han participado en donde se ha implementado la hipoteca inversa (Davidoff y otros, 2017; Nakajima y Telyukova, 2017) como estar solo, tener bajos ingresos, tener mala salud y con un valor de la propiedad más alto que el promedio, el índice de pobreza se ve reducido un $2 \%$. Estos resultados se ajustan a los rangos que presenta la literatura especializada, confirmando así la confiabilidad de nuestros hallazgos, aunque solo a nivel tendencial, porque los eventos aleatorios son incompatibles con la capacidad predictiva que buscamos.

Nuestros hallazgos indican que al implementar la hipoteca inversa al momento de jubilarse los individuos podrían usar en promedio un 59\% de su propiedad como colateral, obteniendo pagos mensuales constantes de 62.508 pesos, lo que equivale a un 60\% del ingreso promedio de los hogares con personas jubiladas. A su vez, lo anterior representa un aumento del 57\% en el ingreso per cápita del contratante. Por otro lado, los pagos mensuales presentan una brecha cuando se hace el análisis por género, de forma que las mujeres reciben un 42,6\% (37.984 pesos) menos que los hombres. Tal diferencia proviene de la mayor esperanza de vida y menor edad de jubilación de las mujeres, lo que aumenta la duración de sus contratos. No obstante, si se incrementa la edad de jubilación de las mujeres a los 65 años, la brecha por género se reduce a un 10,9\% (9.763 pesos). Esto nos indica que de implementar este instrumento a través de políticas públicas, se debe considerar el igualar las condiciones financieras por género; de lo contrario, aunque su aporte mejorará el bienestar de las personas jubiladas y de sus hogares, también podría acentuar las brechas en riqueza por género.

Desde otro punto de vista, nuestras simulaciones nos permitieron analizar de qué manera variarían los pagos mensuales en relación a la edad en que se contrata la hipoteca inversa. Un individuo que contrata el instrumento a los 65 años de edad podría utilizar un 57\% de su propiedad como colateral, pero si lo hace a los 80 años de edad ese porcentaje subiría a un 89\%, lo que pone de manifiesto una relación a tasa creciente entre el monto recibido por hipoteca inversa y la edad a la que se realice dicho contrato. Entonces, al implementar este instrumento, dentro de un contexto de políticas públicas se debe tener en cuenta la dispersión que se obtendrá en los pagos otorgados por este instrumento, debido a la distribución de la edad en que se realice el contrato. También existirá dispersión por la distribución del precio del inmueble, el cual dependerá de su futura plusvalía. Estos elementos le dan diversidad al instrumento financiero, por lo que podría existir más de un tipo de institución financiera interesada en otorgar estos contratos.

En resumen, los resultados que se presentaron en este estudio muestran que la hipoteca inversa es un instrumento útil para el aumento de liquidez en los pensionados. Lo anterior es importante en un contexto donde el $70 \%$ de los chilenos sostiene que las pensiones son insuficientes para mantener un nivel de vida adecuado en la vejez. Más aún, se detalla el relevante potencial social de reducción de la pobreza, lo cual generaría indiscutibles mejoras de bienestar para el grupo objetivo. Lo que prima en la implementación de la hipoteca inversa es que las personas mayores tengan acceso al crédito y así aumentar sus ingresos, sin perjudicar su situación económica actual. No obstante, se debe considerar a los herederos del deudor, ya que este instrumento es una hipoteca y no implica una transferencia del dominio. Esto podría generar un conflicto de intereses entre ambos, requiriéndose de una legislación que brinde herramientas necesarias para proteger tanto a herederos como acreedores (Fuentes y Moris, 2014). 


\section{Bibliografía}

Alonso, J., D. Tuesta y M. Lamuedra (2013), "Potencialidad del desarrollo de hipotecas inversas como complemento pensionario: el caso de Chile", Documento de Trabajo, Nㅜ 9, Madrid, Banco Bilbao Vizcaya Argentaria (BBVA).

Banco Central de Chile (2017), "Base de datos estadísticos. Indicadores sectoriales" [en línea] https://si3. bcentral.cl/Siete/secure/cuadros/arboles.aspx.

Bartel, H. y M. Daly (1980), "Reverse annuity mortgages as a source of retirement income", Canadian Public Policy/Analyse de Politiques, vol. 6, No 4, Toronto, University of Toronto Press.

Comisión Asesora Presidencial sobre el Sistema de Pensiones (2015), Informe final, Santiago [en línea] http:// www.comision-pensiones.cl/Informe_final_CP_2015.pdf.

Davidoff, T. (2010), "Interest accumulation in retirement home equity products", Working Paper, Vancouver, University of British Columbia.

Davidoff, T., P. Gerhard y T. Post (2017), “Reverse mortgages: what homeowners (don't) know and how it matters", Journal of Economic Behavior \& Organization, vol. 133, Amsterdam, Elsevier.

Fornero, E., M. Rossi y M. Urzi (2016), "Explaining why, right or wrong, (Italian) households do not like reverse mortgages", Journal of Pension Economics \& Finance, vol. 15, Nㅜㄹ, Cambridge, Cambridge University Press.

Fuentes, M. y D. Moris (2014), "El futuro de la hipoteca inversa en Chile", tesis para optar al grado de licenciado, Santiago, Universidad de Chile.

Hancock, R. (1998), "Can housing wealth alleviate poverty among Britain's older population?", Fiscal Studies, vol. 19, № 3, Hoboken, Wiley.

INE (Instituto Nacional de Estadísticas) (2010a), Boletín informativo. Enfoque estadístico hombres y mujeres en Chile, Santiago. (2010b), Compendio estadístico año 2010, Santiago.

INE/CEPAL (Instituto Nacional de Estadísticas/Comisión Económica para América Latina y el Caribe) (s/f), Estimaciones y proyecciones de población por sexo y edad. Total país 1950-2050, Santiago.

Kutty, N. (1998), "The scope for poverty alleviation among elderly home-owners in the United States through reverse mortgages", Urban Studies, vol. 35, № 1, Thousand Oaks, Sage.

Ma, S. y Deng (2013), "Evaluation of reverse mortgage programs in Korea", Seoul Journal of Business, vol. 19, № 1, Seúl, Universidad Nacional de Seúl.

Mayer, C. y K. Simons (1994), "Reverse mortgages and the liquidity of housing wealth", Real Estate Economics, vol. 22, № 2, Hoboken, Wiley.

Moscarola, F. y otros (2015), "Reverse mortgage: a tool to reduce old age poverty without sacrificing social inclusion", Ageing in Europe - Supporting Policies for an Inclusive Society, A. Börsch-Supan y otros (eds.), Berlín, Walter De Gruyter.

Moulton, S. y otros (2015), "Who gets a reverse mortgage? Identifying household level determinants of U.S. reverse mortgage choices", ponencia presentada en la XXII Conferencia Anual de la European Real Estate Society (ERES), Estambul, 24 a 27 de junio.

Muñoz, M. (2011), "Hipoteca revertida en Chile: una alternativa para la reducción de la pobreza", tesis para optar al grado de magister, Santiago, Universidad de Chile.

Nakajima, M. e I. Telyukova (2017), "Reverse mortgage loans: a quantitative analysis", The Journal of Finance, vol. 72, № 2, Hoboken, Wiley.

OCDE (Organización de Cooperación y Desarrollo Económicos) (2013), Pensions at a Glance 2013. OECD and G20 Indicators, París.

Ong, R. (2008), "Unlocking housing equity through reverse mortgages: the case of elderly homeowners in Australia", European Journal of Housing Policy, vol. 8, No 1, Abingdon, Taylor \& Francis.

Phillips, W. y S. Gwin (1993), "Reverse mortgages", Transactions of the Society of Actuaries, № 44, Schaumburg, Society of Actuaries .

Rodda, D., C. Herbert y H. Lam (2000), Evaluation Report of FHA's Home Equity Conversion Mortgage Insurance Demonstration, Abt Associates Inc., marzo.

Rodda, D. y otros (2003), Refinancing Premium, National Loan Limit, and Long-Term Care Premium Waiver for FHA's HECM Program, Cambridge, U.S. Department of Housing and Urban Development.

Sáez, R. (2010), "La OCDE y el ingreso de Chile", Estudios Internacionales, vol. 43, № 166, Santiago, Universidad de Chile. 
Superintendencia de Pensiones (2010), El sistema de pensiones en Chile, Santiago.

_ (2009a), "Compendio de normas del sistema de pensiones, Libro III, Título X, Tablas de mortalidad" [en línea] http://www.spensiones.cl/portal/compendio/596/w3-propertyvalue-4350.html.

_ (2009b), "Compendio de Normas del Sistema de Pensiones, Libro III, Título X, Tablas de Mortalidad, Anexo № 5", Santiago [en línea] http://www.spensiones.cl/portal/compendio/596/w3-propertyvalue-4350.html. _ (2006), El sistema de pensiones en Chile, Santiago.

Szymanoski, E. (1994), "Risk and the home equity conversionmortgage", Real Estate Economics, vol. 22, № 2, Hoboken, Wiley.

The Economist (2016), "The perils of not saving", Londres, 27 de agosto.

Wang, P. y J. Kim (2014), "The value of reverse mortgage loans: case study of the Chinese market", Journal of Asian Finance, Economics and Business, vol. 1, № 4, Korea Distribution Science Association. 


\section{Anexo A1}

\section{Modelamiento del precio de las viviendas en distintos períodos}

Para realizar el modelamiento del presente estudio es preciso conocer el precio de las viviendas en períodos distintos al de la toma de la muestra. En concreto, debemos estimar el precio de estas al momento en que vencería el contrato (período posterior a la muestra) y, a su vez, el precio de los inmuebles cuando la persona se jubiló (período anterior a la muestra). Para realizar esto se seguirá el modelo de Szymanoski (1994), el cual se detalla a continuación.

Definimos las siguientes variables:

$$
\begin{gathered}
H_{t}: \text { Precio de la vivienda en el año } t \\
H_{0}: \text { Precio de la vivienda en el año } t=0 \text { inicial }
\end{gathered}
$$

Luego, se tiene que el porcentaje que representa $H_{t}$ con respecto a $H_{0}$ es $X_{t}$ :

A su vez:

$$
X_{t}=\frac{H_{t}}{H_{0}}
$$

$x$ : Variable aleatoria del set de observaciones $X_{t}$

Aplicando logaritmo natural a $X_{t}$ obtenemos el cambio porcentual del precio de la vivienda entre el periodo inicial y " $t$ " arbitrario:

$$
Y_{t}=\ln \left(X_{t}\right) \rightarrow X_{t}=\exp \left(Y_{t}\right)
$$

Donde:

$$
\text { y: Variable aleatoria del set de observaciones } Y_{t}
$$

En este sentido, usando la función exponencial $g(a)=\exp (a)$ tenemos:

$$
g(y)=\exp (y) \rightarrow E(x)=E(\exp (y))=E(g(Y))
$$

En este punto, Szymanoski (1994) sostiene que las tendencias de los precios de viviendas a largo plazo pueden ser modeladas por un proceso de Movimiento Browniano Geométrico (MBG). Consecuentemente se asume que $Y_{t}$ es un MBG, lo cual implica que en el periodo " $t$ ", $Y_{t}$ tiene una media de $\mu \cdot t$ y una desviación estándar de $\sqrt[\sigma]{t}$, describiendo una distribución normal. A su vez, con lo anterior $X_{t}$ queda definido como un MBG con una distribución log-normal.

Consecuentemente, sabemos que, dado $F(y)$ función de probabilidad de " $y$ " y $f(y)$ función de densidad de " $y$ ". De esta manera:

$$
E(g(y))=\int_{-\infty}^{+\infty} g(y) d F(y)=\int_{-\infty}^{+\infty} g(y) f(y) d y
$$


Como se argumentó, la variable " $y$ " sigue una distribución normal, por lo que $f(y)$ es una distribución de densidad normalmente distribuida con media $\mu$ y desviación estándar $\sigma$.

$$
f(y)=\frac{1}{\sigma \sqrt{2 \pi}} \exp \left[-\frac{1}{2}\left(\frac{y-\mu}{\sigma}\right)^{2}\right]
$$

Reemplazando (II) en (I):

$$
E(g(y))=E(\exp (y))=\frac{1}{\sigma \sqrt{2 \pi}} \int_{-\infty}^{+\infty} \exp (y) \cdot \exp \left[-\frac{1}{2}\left(\frac{y-\mu}{\sigma}\right)^{2}\right] d y
$$

Estandarizando lo anterior se reemplaza " $y$ " por $(y-\mu) / \sigma$, lo que da el siguiente resultado:

$$
E(\exp (y))=\exp \left(\mu+0,5 \sigma^{2}\right) \cdot\left(\frac{1}{\sqrt{2 \pi}}\right) \int_{-\infty}^{+\infty} \exp \left[-\frac{1}{2}(y-\sigma)^{2}\right] d y=\exp \left(\mu+0,5 \sigma^{2}\right) \cdot \beta
$$

Donde el valor de $\beta$ es 1:

$$
\beta=\left(\frac{1}{\sqrt{2 \pi}}\right) \int_{-\infty}^{+\infty} \exp \left[-\frac{1}{2}(y-\sigma)^{2}\right] d y=1
$$

A través de las ecuaciones (IV) y $(\mathrm{V})$ se tiene:

$$
E(X)=E(\exp (y))=\exp \left(\mu+0,5 \sigma^{2}\right)
$$

Así, suponiendo $x$ variable estocástica, junto con $\mu$ y $\sigma$ constantes, considerando el tiempo como una función, la ecuación (VI) queda definida como:

$$
E(x(t))=\exp \left(\mu \cdot t+0,5 \sigma^{2} \cdot t\right)
$$

Y de esta manera:

$$
\begin{array}{cc}
E(H(t))=H_{0} \cdot \exp \left(\mu \cdot t+0,5 \sigma^{2} \cdot t\right) & \forall t \geq 0 \\
E(H(t))=\frac{H_{0}}{\exp \left(\mu \cdot t+0,5 \sigma^{2} \cdot t\right)} & \forall t \leq 0
\end{array}
$$




\section{Anexo A2}

Tablas de mortalidad

Cuadro A2.1

Tablas de mortalidad correspondientes a 2009a

(Por edades en la columna de la izquierda, y en porcentajes el resto)

\begin{tabular}{|c|c|c|c|c|c|}
\hline \multirow{3}{*}{ Edad (t) } & \multicolumn{2}{|c|}{ Hombre } & \multicolumn{3}{|c|}{ Mujer } \\
\hline & \multirow{2}{*}{$Q_{t}$} & \multirow{2}{*}{$p_{t}$} & \multirow{2}{*}{$Q_{t}$} & \multirow{2}{*}{$\begin{array}{c}\text { que se jubile a los } 60 \text { años } \\
p_{t}\end{array}$} & \multirow{2}{*}{$\frac{\text { que se jubile a los } 65 \text { años }}{p_{t}}$} \\
\hline & & & & & \\
\hline 60 & & & 0,31 & 1 & \\
\hline 61 & & & 0,33 & 99,69 & \\
\hline 62 & & & 0,37 & 99,36 & \\
\hline 63 & & & 0,40 & 98,99 & \\
\hline 64 & & & 0,44 & 98,60 & \\
\hline 65 & 1,24 & 1 & 0,48 & 98,16 & 1 \\
\hline 66 & 1,36 & 98,76 & 0,53 & 97,69 & 99,52 \\
\hline 67 & 1,49 & 97,42 & 0,57 & 97,17 & 98,99 \\
\hline 68 & 1,64 & 95,97 & 0,63 & 96,62 & 98,43 \\
\hline 69 & 1,81 & 94,39 & 0,69 & 96,01 & 97,81 \\
\hline 70 & 1,99 & 92,68 & 0,76 & 95,35 & 97,13 \\
\hline 71 & 2,20 & 90,84 & 0,85 & 94,62 & 96,40 \\
\hline 72 & 2,42 & 88,84 & 0,95 & 93,82 & 95,58 \\
\hline 73 & 2,66 & 86,69 & 1,08 & 92,93 & 94,67 \\
\hline 74 & 2,92 & 84,38 & 1,23 & 91,93 & 93,65 \\
\hline 75 & 3,23 & 81,92 & 1,40 & 90,79 & 92,49 \\
\hline 76 & 3,36 & 79,27 & 1,59 & 89,52 & 91,20 \\
\hline 77 & 3,91 & 76,61 & 1,82 & 88,10 & 89,75 \\
\hline 78 & 4,31 & 73,62 & 2,08 & 86,50 & 88,12 \\
\hline 79 & 4,75 & 70,45 & 2,38 & 84,70 & 86,28 \\
\hline 80 & 5,26 & 67,10 & 2,73 & 82,68 & 84,23 \\
\hline 81 & 5,87 & 63,57 & 3,14 & 80,42 & 81,93 \\
\hline 82 & 6,56 & 59,84 & 3,60 & 77,90 & 79,36 \\
\hline 83 & 7,31 & 55,91 & 4,13 & 75,10 & 76,50 \\
\hline 84 & 8,16 & 51,83 & 4,73 & 71,99 & 73,34 \\
\hline 85 & 9,08 & 47,60 & 5,41 & 68,59 & 69,87 \\
\hline 86 & 10,07 & 43,28 & 6,17 & 64,88 & 66,09 \\
\hline 87 & 11,13 & 38,92 & 7,03 & 60,87 & 62,01 \\
\hline 88 & 12,27 & 34,59 & 7,97 & 56,60 & 57,65 \\
\hline 89 & 13,46 & 30,34 & 9,01 & 52,08 & 53,06 \\
\hline 90 & 14,17 & 26,26 & 10,14 & 47,39 & 48,28 \\
\hline 91 & 16,02 & 22,54 & 11,37 & 42,59 & 43,38 \\
\hline 92 & 17,37 & 18,93 & 12,70 & 37,74 & 38,45 \\
\hline 93 & 18,75 & 15,64 & 14,12 & 32,95 & 33,57 \\
\hline 94 & 20,22 & 12,71 & 15,64 & 28,30 & 28,83 \\
\hline
\end{tabular}


Cuadro A2.1 (conclusión)

\begin{tabular}{|c|c|c|c|c|c|}
\hline \multirow{3}{*}{ Edad (t) } & \multicolumn{2}{|c|}{ Hombre } & \multicolumn{3}{|c|}{ Mujer } \\
\hline & \multirow{2}{*}{$Q_{t}$} & \multirow{2}{*}{$p_{t}$} & \multirow{2}{*}{$Q_{t}$} & \multirow{2}{*}{$\frac{\text { que se jubile a los } 60 \text { años }}{p_{t}}$} & \multirow{2}{*}{$\begin{array}{c}\text { que se jubile a los } 65 \text { años } \\
p_{t}\end{array}$} \\
\hline & & & & & \\
\hline 95 & 21,74 & 10,14 & 17,24 & 23,87 & 24,32 \\
\hline 96 & 23,32 & 7,93 & 18,93 & 19,76 & 20,13 \\
\hline 97 & 24,93 & 6,08 & 20,72 & 16,02 & 16,32 \\
\hline 98 & 26,59 & 4,57 & 22,60 & 12,70 & 12,94 \\
\hline 99 & 28,36 & 3,35 & 24,62 & 9,83 & 10,01 \\
\hline 100 & 30,26 & 2,40 & 26,30 & 7,41 & 7,55 \\
\hline 101 & 32,26 & 1,68 & 27,71 & 5,46 & 5,56 \\
\hline 102 & 34,42 & 1,13 & 29,61 & 3,95 & 4,02 \\
\hline 103 & 36,71 & 0,74 & 31,65 & 2,78 & 2,83 \\
\hline 104 & 39,15 & 0,47 & 33,82 & 1,90 & 1,93 \\
\hline 105 & 41,76 & 0,29 & 36,15 & 1,26 & 1,28 \\
\hline 106 & 44,53 & 0,17 & 38,36 & 0,80 & 0,82 \\
\hline 107 & 47,50 & 0,09 & 41,29 & 0,49 & 0,50 \\
\hline 108 & 50,66 & 0,05 & 44,12 & 0,29 & 0,30 \\
\hline 109 & 54,02 & 0,02 & 47,16 & 0,16 & 0,17 \\
\hline 110 & 100,00 & 0,01 & 100,00 & 0,09 & 0,09 \\
\hline
\end{tabular}

Fuente: Elaboración propia, sobre la base de Superintendencia de Pensiones de Chile, "Compendio de Normas del Sistema de Pensiones, Libro III, Título X, Tablas de Mortalidad, Anexo No 5", Santiago, 2009 [en línea] http://www.spensiones.cl/ portal/compendio/596/w3-propertyvalue-4350.html.

a Para la elaboración del cuadro y, como en el resto del documento, se supone que los individuos contratan una hipoteca inversa al momento de su jubilación.

\section{Donde}

$Q_{t}=$ Probabilidad de que el individuo no esté vivo en el año $t+1$,estando vivo en $t$.

$p_{t}=$ Probabilidad de sobrevivencia o probabilidad de que el individuo esté vivo en el año $t$, habiendo estado vivo al momento de contratar la hipoteca inversa.

En el caso de las mujeres se presentan dos valores para $P_{t}$. En primer caso se brinda esta variable dada la situación de jubilación actual para el sexo femenino, que es de 60 años. Por su parte, en segunda instancia se muestra esta cifra en el escenario ficticio de que las mujeres se jubilaran a la misma edad que los hombres, es decir a los 65 años.

Por último, figura el cuadro A2.2, que muestra la probabilidad de que un individuo representativo esté vivo a una edad arbitraria representada en cada fila del cuadro, dada una edad de contratación de la hipoteca inversa de entre 65 y 80 años, lo que se observa en las columnas. Así, los valores de este cuadro corresponden al promedio geométrico de las probabilidades de sobrevivencia por sexo ponderadas por el porcentaje de cada sexo en la muestra. 
Cuadro A2.2

Tabla de probabilidades de supervivencia dependiendo de la edad en que un individuo representativo contrate la hipoteca inversa

(Por edades en la columna horizontal y en la primera columna vertical, y en porcentajes el resto)

\begin{tabular}{|c|c|c|c|c|c|c|c|c|c|c|c|c|c|c|c|c|}
\hline & 65 & 66 & 67 & 68 & 69 & 70 & 71 & 72 & 73 & 74 & 75 & 76 & 77 & 78 & 79 & 80 \\
\hline 65 & 100 & & & & & & & & & & & & & & & \\
\hline 66 & 99,2 & 100 & & & & & & & & & & & & & & \\
\hline 67 & 98,3 & 99,1 & 100 & & & & & & & & & & & & & \\
\hline 68 & 97,4 & 98,2 & 99,1 & 100 & & & & & & & & & & & & \\
\hline 69 & 96,4 & 97,2 & 98,0 & 99,0 & 100 & & & & & & & & & & & \\
\hline 70 & 95,3 & 96,1 & 96,9 & 97,8 & 98,9 & 100 & & & & & & & & & & \\
\hline 71 & 94,1 & 94,8 & 95,7 & 96,6 & 97,6 & 98,7 & 100 & & & & & & & & & \\
\hline 72 & 92,8 & 93,5 & 94,3 & 95,2 & 96,2 & 97,4 & 98,6 & 100 & & & & & & & & \\
\hline 73 & 91,3 & 92,1 & 92,9 & 93,8 & 94,7 & 95,8 & 97,1 & 98,4 & 100 & & & & & & & \\
\hline 74 & 89,8 & 90,5 & 91,3 & 92,1 & 93,1 & 94,2 & 95,4 & 96,7 & 98,3 & 100 & & & & & & \\
\hline 75 & 88,0 & 88,7 & 89,5 & 90,4 & 91,3 & 92,4 & 93,6 & 94,9 & 96,4 & 98,1 & 100 & & & & & \\
\hline 76 & 86,1 & 86,8 & 87,6 & 88,4 & 89,4 & 90,4 & 91,5 & 92,9 & 94,3 & 96,0 & 97,9 & 100 & & & & \\
\hline 77 & 84,1 & 84,8 & 85,6 & 86,4 & 87,3 & 88,3 & 89,4 & 90,7 & 92,1 & 93,8 & 95,6 & 97,7 & 100 & & & \\
\hline 78 & 81,9 & 82,5 & 83,3 & 84,1 & 85,0 & 85,9 & 87,0 & 88,3 & 89,7 & 91,2 & 93,0 & 95,1 & 97,3 & 100 & & \\
\hline 79 & 79,4 & 80,1 & 80,8 & 81,6 & 82,4 & 83,4 & 84,4 & 85,6 & 87,0 & 88,5 & 90,2 & 92,2 & 94,4 & 97,0 & 100 & \\
\hline 80 & 76,8 & 77,4 & 78,1 & 78,8 & 79,7 & 80,6 & 81,6 & 82,8 & 84,1 & 85,6 & 87,2 & 89,1 & 91,3 & 93,8 & 96,7 & 100 \\
\hline 81 & 73,9 & 74,5 & 75,1 & 75,9 & 76,7 & 77,5 & 78,5 & 79,7 & 80,9 & 82,3 & 83,9 & 85,8 & 87,8 & 90,2 & 93,0 & 96,2 \\
\hline 82 & 70,7 & 71,3 & 71,9 & 72,6 & 73,4 & 74,2 & 75,2 & 76,3 & 77,5 & 78,8 & 80,4 & 82,1 & 84,1 & 86,4 & 89,1 & 92,1 \\
\hline 83 & 67,3 & 67,9 & 68,5 & 69,1 & 69,9 & 70,7 & 71,6 & 72,6 & 73,7 & 75,0 & 76,5 & 78,2 & 80,0 & 82,2 & 84,8 & 87,7 \\
\hline 84 & 63,7 & 64,2 & 64,8 & 65,4 & 66,1 & 66,8 & 67,7 & 68,7 & 69,7 & 71,0 & 72,3 & 73,9 & 75,7 & 77,8 & 80,2 & 82,9 \\
\hline 85 & 59,8 & 60,3 & 60,8 & 61,4 & 62,0 & 62,7 & 63,5 & 64,4 & 65,5 & 66,6 & 67,9 & 69,4 & 71,0 & 73,0 & 75,2 & 77,9 \\
\hline 86 & 55,7 & 56,1 & 56,6 & 57,1 & 57,7 & 58,4 & 59,1 & 60,0 & 60,9 & 62,0 & 63,2 & 64,6 & 66,1 & 68,0 & 70,0 & 72,5 \\
\hline 87 & 51,3 & 51,7 & 52,2 & 52,7 & 53,2 & 53,9 & 54,6 & 55,3 & 56,2 & 57,2 & 58,3 & 59,6 & 61,0 & 62,7 & 64,6 & 66,8 \\
\hline 88 & 46,9 & 47,2 & 47,6 & 48,1 & 48,6 & 49,2 & 49,8 & 50,5 & 51,3 & 52,2 & 53,2 & 54,4 & 55,7 & 57,2 & 59,0 & 61,0 \\
\hline 89 & 42,3 & 42,6 & 43,0 & 43,4 & 43,9 & 44,4 & 45,0 & 45,6 & 46,3 & 47,1 & 48,1 & 49,1 & 50,3 & 51,7 & 53,2 & 55,1 \\
\hline 90 & 37,7 & 38,0 & 38,4 & 38,7 & 39,1 & 39,6 & 40,1 & 40,7 & 41,3 & 42,0 & 42,8 & 43,8 & 44,8 & 46,1 & 47,5 & 49,1 \\
\hline 91 & 33,3 & 33,5 & 33,8 & 34,2 & 34,5 & 34,9 & 35,4 & 35,9 & 36,4 & 37,1 & 37,8 & 38,6 & 39,5 & 40,6 & 41,9 & 43,3 \\
\hline 92 & 28,9 & 29,1 & 29,3 & 29,6 & 29,9 & 30,3 & 30,7 & 31,1 & 31,6 & 32,2 & 32,8 & 33,5 & 34,3 & 35,2 & 36,3 & 37,6 \\
\hline 93 & 24,6 & 24,8 & 25,1 & 25,3 & 25,6 & 25,9 & 26,2 & 26,6 & 27,0 & 27,5 & 28,0 & 28,6 & 29,3 & 30,1 & 31,0 & 32,1 \\
\hline 94 & 20,7 & 20,9 & 21,0 & 21,2 & 21,5 & 21,7 & 22,0 & 22,3 & 22,7 & 23,1 & 23,5 & 24,0 & 24,6 & 25,3 & 26,0 & 27,0 \\
\hline 95 & 17,1 & 17,2 & 17,4 & 17,5 & 17,7 & 17,9 & 18,1 & 18,4 & 18,7 & 19,0 & 19,4 & 19,8 & 20,3 & 20,8 & 21,5 & 22,2 \\
\hline 96 & 13,8 & 13,9 & 14,0 & 14,2 & 14,3 & 14,5 & 14,7 & 14,9 & 15,1 & 15,4 & 15,7 & 16,0 & 16,4 & 16,9 & 17,4 & 18,0 \\
\hline 97 & 11,0 & 11,0 & 11,1 & 11,2 & 11,4 & 11,5 & 11,6 & 11,8 & 12,0 & 12,2 & 12,4 & 12,7 & 13,0 & 13,4 & 13,8 & 14,3 \\
\hline 98 & 8,5 & 8,6 & 8,6 & 8,7 & 8,8 & 8,9 & 9,0 & 9,2 & 9,3 & 9,5 & 9,6 & 9,9 & 10,1 & 10,4 & 10,7 & 11,1 \\
\hline 99 & 6,4 & 6,5 & 6,5 & 6,6 & 6,7 & 6,8 & 6,8 & 6,9 & 7,0 & 7,2 & 7,3 & 7,5 & 7,6 & 7,9 & 8,1 & 8,4 \\
\hline 100 & 4,8 & 4,8 & 4,8 & 4,9 & 4,9 & 5,0 & 5,1 & 5,1 & 5,2 & 5,3 & 5,4 & 5,5 & 5,6 & 5,8 & 6,0 & 6,2 \\
\hline 101 & 3,4 & 3,5 & 3,5 & 3,5 & 3,6 & 3,6 & 3,6 & 3,7 & 3,8 & 3,8 & 3,9 & 4,0 & 4,1 & 4,2 & 4,3 & 4,5 \\
\hline 102 & 2,4 & 2,4 & 2,5 & 2,5 & 2,5 & 2,5 & 2,6 & 2,6 & 2,6 & 2,7 & 2,7 & 2,8 & 2,9 & 2,9 & 3,0 & 3,1 \\
\hline 103 & 1,7 & 1,7 & 1,7 & 1,7 & 1,7 & 1,7 & 1,8 & 1,8 & 1,8 & 1,8 & 1,9 & 1,9 & 2,0 & 2,0 & 2,1 & 2,1 \\
\hline 104 & 1,1 & 1,1 & 1,1 & 1,1 & 1,1 & 1,1 & 1,2 & 1,2 & 1,2 & 1,2 & 1,2 & 1,3 & 1,3 & 1,3 & 1,4 & 1,4 \\
\hline 105 & 0,7 & 0,7 & 0,7 & 0,7 & 0,7 & 0,7 & 0,7 & 0,8 & 0,8 & 0,8 & 0,8 & 0,8 & 0,8 & 0,9 & 0,9 & 0,9 \\
\hline 106 & 0,4 & 0,4 & 0,4 & 0,4 & 0,4 & 0,5 & 0,5 & 0,5 & 0,5 & 0,5 & 0,5 & 0,5 & 0,5 & 0,5 & 0,5 & 0,6 \\
\hline 107 & 0,3 & 0,3 & 0,3 & 0,3 & 0,3 & 0,3 & 0,3 & 0,3 & 0,3 & 0,3 & 0,3 & 0,3 & 0,3 & 0,3 & 0,3 & 0,3 \\
\hline 108 & 0,1 & 0,1 & 0,1 & 0,1 & 0,1 & 0,2 & 0,2 & 0,2 & 0,2 & 0,2 & 0,2 & 0,2 & 0,2 & 0,2 & 0,2 & 0,2 \\
\hline 109 & 0,1 & 0,1 & 0,1 & 0,1 & 0,1 & 0,1 & 0,1 & 0,1 & 0,1 & 0,1 & 0,1 & 0,1 & 0,1 & 0,1 & 0,1 & 0,1 \\
\hline 110 & 0,0 & 0,0 & 0,0 & 0,0 & 0,0 & 0,0 & 0,0 & 0,0 & 0,0 & 0,0 & 0,0 & 0,0 & 0,0 & 0,0 & 0,0 & 0,0 \\
\hline
\end{tabular}

Fuente: Elaboración propia, sobre la base de Superintendencia de Pensiones de Chile, "Compendio de Normas del Sistema de Pensiones, Libro III, Título X, Tablas de Mortalidad, Anexo No 5", Santiago, 2009 [en línea] http://www.spensiones.cl/ portal/compendio/596/w3-propertyvalue-4350.html. 


\section{Anexo A3}

\section{Estadística descriptiva de la muestra}

Cuadro A3.1

Estadística descriptiva de la muestra

\begin{tabular}{|c|c|c|c|c|}
\hline Variable & Media & Desvío estándar & Mínimo & Máximo \\
\hline Sexo (Hombre = 1) (en porcentajes) & 40,92 & 45,76 & 0 & 1 \\
\hline Edad & 71,22 & 7,96 & 60 & 96 \\
\hline Jefe del hogar (jefe de hogar = 1) (en porcentajes) & 65,09 & 47,68 & 0 & 1 \\
\hline Ingreso del hogar (en pesos del 2009) & 103,75 & 136,58 & 0 & 2000,00 \\
\hline Ingreso per cápita (en pesos de 2009) & 34,72 & 49,53 & 0 & 450,00 \\
\hline Índice de pobreza (en porcentajes) & 86,25 & 34,44 & 0 & 1 \\
\hline Precio vivienda imputado (en millones de pesos de 2009) & 20,40 & 4,11 & 2,50 & 50,00 \\
\hline
\end{tabular}

Fuente: Elaboración propia, sobre la base de la Encuesta de Protección Social, 2009.

Nota: Cuadro elaborado en base a 2.627 observaciones que representan a una población de 1.623 .326 individuos. 


\section{Anexo A4}

\section{Pagos de hipoteca inversa según edad de contratación}

\section{Cuadro A4.1}

Pagos de hipoteca inversa según edad de contratación

(En pesos chilenos)

\begin{tabular}{ccc}
\hline Precio de la vivienda al jubilarse & 14,00 millones de pesos de 2009 & 20,04 millones de pesos de 2009 \\
\hline Edad de contratación & Pagos mensuales Caso 1 & Pagos mensuales Caso 2 \\
\hline 65 & 62387 & 907 \\
\hline 66 & 65453 & 100166 \\
\hline 67 & 68741 & 105312 \\
\hline 68 & 72273 & 110850 \\
\hline 69 & 76074 & 116832 \\
\hline 70 & 80179 & 123297 \\
\hline 71 & 84616 & 130588 \\
\hline 72 & 89619 & 138387 \\
\hline 73 & 94972 & 146860 \\
\hline 74 & 100786 & 156031 \\
\hline 75 & 107080 & 165965 \\
\hline 76 & 113898 & 176930 \\
\hline 77 & 121423 & 188751 \\
\hline 78 & 129535 & 202790 \\
\hline 79 & 139169 & 218270 \\
\hline
\end{tabular}

Fuente: Elaboración propia, sobre la base de la Encuesta de Protección Social, 2009. 